TẠP CHÍ KHOA HỌC ĐẠI HỌC TÂN TRÀO
ISSN: 2354 - 1431

\title{
Sự phát triển tư duy lý luận của Đảng về xây dựng văn hóa, con người Việt Nam trong thò̀i kỳ mới
}

\author{
Bùi Bạch Đằng ${ }^{a *}$ \\ ${ }^{a}$ Truò̀ng Đại học Chính trị, Bộ Quốc phòng \\ "Email: bachbui0410@gmail.com
}

\section{Thông tin bài viết}

Ngày nhận bài:

30/12/2019

Ngày duyệt đăng:

$10 / 3 / 2020$

\section{Tù khóa:}

Tu duy lý luận của Đảng;

nền văn hóa Việt Nam; thời

kỳ đổi mói $i$

\section{Tóm tắt}

Văn hóa có vai trò hết sức quan trọng trong đời sống xã hội, văn hóa luôn đi trước để dọn đường, đi cùng để tập hợp hiệu triệu và đi sau để hoàn tất các cuộc cách mạng xã hội. Trong quá trình lãnh đạo cách mạng, Đảng Cộng sản Việt Nam đã có những bước phát triển mới trong tư duy lý luận về văn hóa, con ngời Việt Nam để văn hóa thực sự trở thành nền tảng tinh thần của xã hội, vừa là mục tiêu, vừa là động lực thúc đẩy sự phát triển bền vững đất nước.

\section{1. Đặt vấn đề}

Đảng và Nhà nước ta rất coi trọng xây dựng văn hóa, con người Việt Nam, điều đó không chỉ bắt nguồn từ truyền thống lịch sử của dân tộc, mà còn là sự khẳng định tư duy lý luận của Đảng trên lĩnh vực văn hóa.

\section{Nội dung}

2.1. Tu duy lý luận của Đảng về xây dụng văn hóa, con người Việt Nam

Văn hóa là toàn bộ giá trị vật chất và tinh thần do con người sáng tạo ra bằng lao động và hoạt động thực tiễn trong lịch sử của mình, biểu hiện trình độ phát triển xã hội trong từng thời kỳ lịch sử nhất định. Nhận thức rõ vai trò và ý nghĩa quan trọng của văn hóa, ngay từ những ngày đầu lãnh đạo cách mạng, Đảng Cộng sản Đông Dương (nay là Đảng Cộng sản Việt Nam) đã đặc biệt quan tâm xây dựng nền văn hóa mới, nhất là trong bối cảnh đất nước đang bộn bề công việc, gấp rút chuẩn bị khởi nghĩa giành chính quyền cách mạng nhưng Thường vụ Trung ương Đảng đã tích cực chuẩn bị và thông qua Đề cương văn hóa Việt Nam (2/1943). Điều đó không chỉ nói lên tầm quan trọng đặc biệt của văn hóa đối với chính trị, xã hội mà còn khẳng định sự sáng suốt, tài tình của Đảng đối với quá trình lãnh đạo cách mạng. Bản Đề cương văn hóa là kết quả của tư duy lý luận và tổng kết kinh nghiệm hoạt động lãnh đạo của Đảng trên mặt trận văn hóa; là đỉnh cao trí tuệ, sự nhận thức sắc bén về tình hình; là những dự báo khoa học về mục tiêu, tính chất, nguyên tắc, nhiệm vụ của văn hóa; là sức mạnh tinh thần to lớn mà cuộc cách mạng giải phóng dân tộc đang cần. Bản Đề cương văn hóa còn xác định văn hóa là một trong ba mặt trận: chính trị, kinh tế, văn hóa và nêu bật những quan điểm, tư tưởng chỉ đạo cách mạng văn hóa là phải hoàn thành cách mạng văn hóa mới hoàn thành cuộc cải tạo xã hội; xác định mục tiêu trước mắt là xây dựng nền văn hóa mới với tính chất dân tộc và dân chủ. Nội hàm chủ yếu của văn hóa bao gồm: Tư tưởng, học thuật và nghệ thuật.

Trong sự nghiệp đổi mới toàn diện đất nước và hội nhập quốc tế, tư duy lý luận của Đảng về xây dựng nền văn hóa ngày càng được bổ sung và phát triển. Nghị quyết Đại hội VI (1986) của Đảng chỉ rõ: "Mỗi hoạt động văn hoá, văn nghệ đều phải tính đến hiệu quả xã hội, tác động tốt đến tư tưởng, tâm lý, tình cảm, nâng cao trình độ giác ngộ xã hội chủ nghĩa và 
trình độ thẩm mỹ của nhân dân" [1, tr. tr.91]. Sự đổi mới tư duy lý luận của Đảng về văn hóa được đề ra đúng vào dịp UNESCO phát động Thập kỷ Quốc tế phát triển văn hóa (1988 - 1997) với định hướng lớn là văn hóa vì sự phát triển, giữ gìn bản sắc văn hóa và đa dạng văn hóa. Đây là sự thể hiện tầm nhìn và tư duy bắt nhịp với xu thế thời đại của Đảng. Tại Hội Trung ương 4 khóa VII (1993), Đảng ta càng thấy rõ vai trò quan trọng của văn hóa và chủ trương coi văn hoá là nền tảng tinh thần của xã hội, một động lực thúc đẩy sự phát triển kinh tế - xã hội, đồng thời là một mục tiêu của chủ nghĩa xã hội. Nghị quyết Đại hội lần thứ VIII (1996) Đảng ta xác định văn hóa không chỉ là động lực mà còn là mục tiêu của phát triển, đó là hai mặt thống nhất trong mục tiêu phát triển văn hóa. Xây dựng và phát triển kinh tế phải nhằm mục tiêu văn hóa, vì xã hội công bằng, văn minh, con người phát triển toàn diện. Nghị quyết nhấn mạnh "Văn hóa... vừa là mục tiêu vừa là động lực thúc đẩy sự phát triển kinh tế - xã hội. Mọi hoạt động văn hóa, văn nghệ phải nhằm xây dựng và phát triển nền văn hóa tiên tiến, đậm đà bản sắc dân tộc, xây dựng con người Việt Nam về tư tưởng, đạo đức, tâm hồn, tình cảm, lối sống,..." [2, tr. 110 - 111]. Như vậy, tư duy mới của Đảng về văn hóa đã góp phần phát huy giá trị nền tảng cốt lõi của dân tộc, đồng thời ngăn chặn những tác động tiêu cực khi mở cửa, hội nhập kinh tế quốc tế.

Nghị quyết Trung ương 5 khóa VIII của Đảng thể hiện bước chuyển quan trọng về tư duy lý luận, năng lực đúc kết thực tiễn những năm đầu đổi mới; chứa đựng nhiều giá trị tư tưởng, nhân văn và khoa học có giá trị về cả lý luận và thực tiễn sâu sắc. Trong đó, quan điểm văn hóa là mục tiêu và động lực thúc đẩy sự phát triển kinh tế - xã hội thể hiện sự đổi mới mạnh mẽ, khẳng định mối quan hệ giữa văn hóa với chính trị và kinh tế: "Xây dựng và phát triển kinh tế phải nhằm mục tiêu văn hóa, vì xã hội công bằng, văn minh, con người phát triển toàn diện. Văn hóa là kết quả của kinh tế đồng thời là động lực của phát triển kinh tế. Các nhân tố văn hóa phải gắn kết chặt chẽ với đời sống và hoạt động xã hội trên mọi phương diện chính trị, kinh tế, xã hội, luật pháp, kỷ cương...” [3, tr. 55]. Đây chính là thành quả đúc kết từ thực tiễn lãnh đạo cách mạng và kế thừa những giá trị tư tưởng quý báu về văn hóa của chủ nghĩa Mác - Lênin và Chủ tịch Hồ Chí Minh. Nghị quyết Trung ương 5 khóa VIII được ví như "Cương lĩnh văn hóa" của Đảng, dân tộc Việt Nam trong thời kỳ quá độ đi lên chủ nghĩa xã hội và hội nhập quốc tế. Nghị quyết đã đáp ứng đúng yêu cầu phát triển của đất nước và nguyện vọng của nhân dân, được xã hội nhiệt thành ủng hộ, đồng tâm thực hiện, góp phần quan trọng vào việc giữ vững ổn định chính trị, tạo động lực thúc đẩy kinh tế - xã hội phát triển, mở rộng giao lưu văn hóa quốc tế, củng cố và tăng cường tiềm lực và "sức mạnh mềm" cho quốc gia.

Tư duy về văn hóa của Đảng tiếp tục có sự phát triển khi Hội nghị Trung ương 10 khóa IX nhấn mạnh phải bảo đảm sự gắn kết giữa nhiệm vụ phát triển kinh tế là trung tâm, xây dựng, chỉnh đốn Đảng là then chốt với không ngừng nâng cao văn hóa - nền tảng tinh thần của xã hội; tạo nên sự phát triển đồng bộ của 3 lĩnh vực trên chính là điều kiện quyết định bảo đảm sự phát triển toàn diện và bền vững của đất nước. Như vậy, lần đầu tiên văn hóa đã trở thành một trong "3 chân kiềng" cũng có thể là gọi là 3 "trụ cột" quan trọng nhất để tạo cơ sở, nền móng xây dựng và phát triển đất nước. Theo đó, Cương lĩnh xây dựng đất nước trong thời kỳ quá độ lên chủ nghĩa xã hội năm 2011 đã nêu lên định hướng về văn hóa với nội hàm toàn diện, sâu sắc là xây dựng nền văn hóa tiên tiến, đậm đà bản sắc dân tộc, phát triển toàn diện, thống nhất trong đa dạng, thấm nhuần sâu sắc tinh thần nhân văn, dân chủ, tiến bộ; làm cho văn hóa gắn kết chặt chẽ và thấm sâu vào toàn bộ đời sống xã hội, trở thành nền tảng tinh thần vững chắc, sức mạnh nội sinh quan trọng của phát triển.

Trước yêu cầu đòi hỏi mới của sự nghiệp cách mạng, tại Hội nghị Trung ương 9 khóa XI, Đảng đã ban hành Nghị quyết 33-NQ/TW về xây dựng và phát triển văn hóa, con người Việt Nam đáp ứng yêu cầu phát triển bền vững đất nước. Nghị quyết khẳng định xây dựng nền văn hóa và con người Việt Nam phát triển toàn diện, hướng đến chân - thiện - mỹ, thấm nhuần tinh thần dân tộc, nhân văn, dân chủ và khoa học. Đây là lần đầu tiên Đảng ta nhấn mạnh quan điểm văn hóa phải được đặt ngang hàng với kinh tế, chính trị, xã hội. Do đó, mọi chủ trương của Đảng phải luôn quan tâm và hướng đến xây dựng văn hóa, coi trọng văn hóa, đề cao "sức mạnh mềm" của đất nước. Vì suy cho cùng, mọi sự phát triển đều xoay quanh, hướng tới sự phát triển, hoàn thiện con người với tư cách là một nhân cách văn hóa hoàn chỉnh nhất. Do đó, bên cạnh việc đề ra các cơ chế, chính sách, giải pháp nhằm không ngừng nâng cao đời sống văn hóa của nhân dân, xây dựng hình ảnh văn hóa Việt Nam ngày càng có sức lan tỏa trên thế giới, Đảng ta cần có nhiều định hướng quan trọng để xây dựng nền tảng tinh thần xã hội lành mạnh. 
Trong tình hình mới, tư duy lý luận của Đảng về văn hóa tiếp tục được Đại hội XII (2016) bổ sung: "Xây dựng nền văn hóa và con người Việt Nam phát triển toàn diện, hướng đến chân - thiện - mỹ, thấm nhuần tinh thần dân tộc, nhân văn, dân chủ và khoa học. Văn hóa thực sự trở thành nền tảng tinh thần vững chắc của xã hội, là sức mạnh nội sinh quan trọng bảo đảm sự phát triển bền vững và bảo vệ vững chắc Tổ quốc vì mục tiêu dân giàu, nước mạnh, dân chủ, công bằng, văn minh" [6, tr.126]. Điều đó cho thấy tư duy lý luận của Đảng đã phản ánh đúng bản chất con người cũng như bản chất văn hóa. Vấn đề văn hóa thực chất là vấn đề con người và vấn đề con người thì kết tinh, cốt lõi nhất ở nội dung, giá trị văn hóa. Tư duy lý luận của Đảng còn thể hiện sâu sắc về mối quan hệ giữa xây dựng con người Việt Nam phát triển toàn diện với mục tiêu của chiến lược phát triển đất nước. Xây dựng con người Việt Nam phát triển toàn diện phải trở thành một mục tiêu của chiến lược phát triển. Đây là sự thể hiện tiếp nối mục tiêu có tính chiến lược lâu dài về xây dựng, phát triển văn hóa, con người Việt Nam, là sự thể hiện sâu sắc về mối quan hệ giữa xây dựng con người Việt Nam phát triển toàn diện với mục tiêu của chiến lược phát triển đất nước. Xây dựng và hoàn thiện hệ giá trị nhân cách con người Việt Nam trong thời kỳ mới là đúc kết và xây dựng hệ giá trị văn hóa và hệ giá trị chuẩn mực của con người Việt Nam thời kỳ công nghiệp hóa, hiện đại hóa và hội nhập quốc tế. Làm cho giá trị văn hóa thấm sâu vào mọi lĩnh vực, mọi mặt hoạt động, mọi quan hệ xã hội, thành sức mạnh nội sinh quan trọng của phát triển bền vững. Xây dựng môi trường văn hóa lành mạnh, tạo điều kiện để xây dựng con người Việt Nam đẹp về nhân cách, đạo đức, tâm hồn; cao về trí tuệ, năng lực, kỹ năng sáng tạo; khỏe về thể chất; nâng cao trách nhiệm xã hội, nghĩa vụ công dân, ý thức tôn trọng, tuân thủ pháp luật; phát huy tốt vai trò chủ thể sáng tạo trong sự nghiệp xây dựng, bảo vệ Tổ quốc.

Như vậy cùng với quá trình lãnh đạo cách mạng, trong mỗi bước đi lên của đất nước, mỗi sự phát triển về tư duy lý luận, Đảng ta đã có những bước tiên phong "khai phá" nâng tầm nhận thức, tư duy về văn hóa, từ việc xác định văn hóa là một trong ba mặt trận mà người cộng sản phải quan tâm được khẳng định trong Đề cương văn hóa Việt Nam năm 1943 đến một trong ba cuộc cách mạng phải tiến hành đồng thời do Đại hội IV xác định; rồi nâng tầm văn hóa là nền tảng tinh thần xã hội, vừa mục tiêu vừa là động lực thúc đẩy sự phát triển kinh tế - xã hội do Hội nghị Trung ương 5 khóa VIII chỉ ra; đến khẳng định văn hóa là một trong ba yếu tố then chốt quyết định sự phát triển toàn diện, bền vững của đất nước do Hội nghị Trung ương 10 khóa IX xác định. Văn hóa trở thành sức mạnh nội sinh quan trọng của sự phát triển do Cương lĩnh năm 2011 xác định; và mới đây văn hóa phải được đặt ngang hàng với kinh tế, chính trị, xã hội do Nghị quyết Trung ương 9 khóa XI chỉ ra. Đặc biệt, tư duy lý luận của Đảng về văn hóa do Đại hội XII xác định là bước tiến mới, những định hướng chính trị hướng dẫn toàn Đảng, toàn dân, toàn quân thực hiện, tạo những chuyển biến mới trong đời sống văn hoá, xã hội. Như vậy, sự phát triển tư duy văn hóa của Đảng không chỉ khẳng định bản chất cách mạng của một đảng Mác-xít chân chính mà còn thể hiện sự tìm tòi, sáng tạo để không ngừng hoàn thiện hệ thống lý luận khoa học của Đảng Cộng sản Việt Nam về văn hóa. Do đó, những quan điểm về văn hóa của Đảng chính là kim chỉ nam chỉ đường, dẫn lối để nhân dân ta xây dựng nền văn hóa với mục tiêu cao cả Tổ quốc ta mãi mãi là một quốc gia văn hiến, dân tộc ta là một dân tộc văn hóa, nền văn hóa nước ta không ngừng phát triển, xứng đáng với tầm vóc dân tộc trong lịch sử và trong thế giới hiện đại.

\subsection{Vận dụng trong xây dụng, phát triển con người mới xã hội chủ nghĩa ở Việt Nam hiện nay}

Trong thời kỳ đẩy mạnh sự nghiệp công nghiệp, hóa hiện đại hóa gắn với phát triển nền kinh tế tri thức; trước sự bùng nổ của cách mạng khoa học công nghệ, nhất là công nghệ thông tin. Quán triệt và thực hiện đường lối, quan điểm của Đảng về xây dựng, phát triển con người mới xã hội chủ nghĩa ở Việt Nam hiện nay, cần tập trung vào một số vấn đề sau:

Thư nhất, phải có chiến lược quốc gia về phát triển con người Việt Nam giai đoạn mới. Đảng ta đã nhận thức rõ vấn đề này, theo đó Đảng ta khẳng định: "Sớm có chiến lực quốc gia về xây dựng gia đình Việt Nam, góp phần giữ gìn và phát triển những giá trị truyền thống của văn hóa, con người Việt Nam, nuôi dưỡng, giáo dục thế hệ trẻ. Đoàn kết và xây dựng hệ giá trị chung của con người Việt Nam trong thời kỳ đẩy mạnh công nghiệp hóa, hiện đại hóa và hội nhập quốc tế" [4, tr.223]. Tuy nhiên, khi xây dụng chiến lược này phải thấu triệt quan điểm của Đảng, luôn hướng đến con người, tất cả vì con người. Chủ trương, chính sách phải cụ thể rõ ràng trong việc xác định mục đích, tiêu chuẩn, nguyên tắc cho các tổ chức, cá nhân theo đó thực hiện. Vì vậy, trước hết, cần phải đổi mới tư duy và phương thức lãnh đạo của Đảng đối với việc xây dựng con người trên cơ sở phát huy tính chủ động 
sáng tạo của Nhà nước trong việc thể chế hóa đường lối, quan điểm của Đảng, đổi mới công tác quản lý của các cơ quan giáo dục đào tạo, văn hóa, xã hội, y tế, thể thao nhằm tạo ra hợp lực chung của tất cả các ngành, các cấp, của cả xã hội trong việc thực hiện chiến lược xây dựng con người. Xây dựng cơ chế phối hợp và chia sẻ trách nhiệm giữa các lĩnh vực chính trị, kinh tế và văn hóa để nâng cao chất lượng và hiệu của việc xây dựng con người.

Thú hai, cần xây dựng hệ giá trị chuẩn của con người Việt Nam trong thời đại mới.Tức là phải :"Đúc kết và xây dựng hệ giá trị văn hóa và hệ giá trị chuẩn mực của con người Việt Nam thời kỳ công nghiệp hóa, hiện đại hóa và hội nhập quốc tế" [6, tr.126 127]. Phải xây dựng được hệ giá trị văn hóa và hệ giá trị chuẩn mực của con người Việt Nam trong thời đại mới thì mới có căn cứ để xây dựng con người. Các hệ giá trị văn hóa và hệ giá trị chuẩn mực của con người Việt Nam phải vừa phù hợp với những giá trị văn hóa truyền thống của dân tộc, vừa phải phù hợp với những giá trị văn hóa của thời đại nhằm xây dựng con người Việt Nam với đầy đủ phẩm chất và năng lực, vừa phải mang tính dân tộc, hiện đại, nhân văn; vừa có khả năng đảm nhiệm những trọng trách mới trong quá trình công nghiệp hoá, hiện đại hoá, hội nhập quốc tế và bảo vệ Tổ quốc xã hội chủ nghĩa trong tình hình mới. Hệ giá trị chuẩn này là cơ sở để các lĩnh vực: văn hóa, y tế, giáo dục..., các ngành các cấp có căn cứ để vun đắp cho con người Việt Nam những giá trị, tùy theo lĩnh vực hoạt động của mình. Đi đôi với đó phải có cơ chế để “đẩy lùi cái xấu, cái ác, thấp hèn, lạc hậu; chống các quan điểm, hành vi sai trái, tiêu cực... làm tha hóa con người. Có giải pháp khắc phục những mặt hạn chế của con người Việt Nam" [5, tr.51].

Thư $b a$, tiếp tục đẩy mạnh sự nghiệp công nghiệp hóa, hiện đại hóa, phát triển kinh tế xã hội gắn với phát triển nhanh và bền vững. Thực chất tập trung phát triển kinh tế, xóa đói giảm nghèo, nâng cao thu nhập, nâng cao mức sống cho nhân dân, qua đó tạo ra những điều kiện vật chất phục vụ cho con người phát triển thông qua việc đáp ứng tốt các nhu cầu ăn, ở, mặc, đi lại... Giải quyết vấn đề trên còn tạo cơ hội bình đẳng trong tiếp cận các nguồn lực phát triển và hưởng thụ các dịch vụ cơ bản, các phúc lợi xã hội, giảm chênh lệch mức sống giữa nông thôn và thành thị, giữa các vùng trong cả nước. Đây là những cơ hội cho con người cải thiện điều kiện sinh hoạt vật chất của mình làm nền tảng để phát triển toàn diện. Tuy nhiên, phát triển kinh tế phải gắn với phát triển văn hóa mới tạo ra sự phát triển bền vững, như vậy, đi đôi với việc phát triển kinh tế phải phát triển văn hóa.

Thư tux, phải chăm lo phát triển văn hóa. Văn hóa là nền tảng tinh thần của xã hội, là sức mạnh nội sinh làm cho xã hội phát triển bền vững, văn hóa còn nuôi dưỡng các giá trị người, là thước đo trình độ phát triển người, làm cho con người phát triển toàn diện. Từ vai trò của văn hóa đối với sự phát triển con người và xã hội, phải quán triệt và thực hiện tốt 5 mục tiêu, 6 nhiệm vụ và 4 giải pháp mà Nghị quyết TW 9 khóa XI đề ra, trong đó tập trung: "Phát triển văn hóa vì sự hoàn thiện nhân cách con người và xây dựng con người để phát triển văn hóa. Trong xây dựng văn hóa, trọng tâm là chăm lo xây dựng con người có nhân cách, lối sống tốt đẹp, với các đặc tính cơ bản: yêu nước, nhân ái, nghĩa tình, trung thực, đoàn kết, cần cù, sáng tạo" [5, tr.48]. Như vậy, tiếp tục đổi mới phương thức lãnh đạo của Đảng đối với lĩnh vực văn hóa, phải tiếp tục phát triển sâu rộng và nâng cao chất lượng nền văn hóa tiên tiến, đậm đà bản sắc dân tộc, xây dựng văn hóa trong kinh tế và chính trị, làm cho văn hóa thấm sâu vào mọi lĩnh vực của đời sống xã hội. Xây dựng, hoàn thiện đi đôi với nâng cao chất lượng, hiệu quả hoạt động của các thiết chế văn hóa.

Thứ năm, kiên trì thực hiện đổi mới toàn diện nền giáo dục Việt Nam. Giáo dục đào tạo có vai trò đặc biệt quan trọng trong phát triển con người, cung cấp cho con người tri thức, kỹ năng kỹ xảo để mỗi người phát triển mình và phát triển xã hội. Vì vậy, đổi mới toàn diện nền giáo dục Việt Nam nhằm đào tạo ra những con người mới đáp ứng yêu cầu của xã hội hiện đại, thông qua đó con người Việt Nam cũng được phát triển cả về thể chất lẫn tinh thần, tri thức cũng như kỹ năng. Tập trung đổi mới mạnh mẽ nội dung chương trình, phương pháp giáo dục theo hướng coi trọng phát triển phẩm chất, năng lực của người học; nội dung giáo dục cần được đổi mới, bổ sung phát triển về phẩm chất, năng lực ở con người theo yêu cầu sự phát triển xã hội; phương pháp giáo dục phải coi trọng khả năng thực hành của người học, gắn lý luận với thực tiễn... Bên cạnh đó, phải phát triển đội ngũ nhà giáo và cán bộ quản lý, đáp ứng yêu cầu đổi mới giáo dục và đào tạo. Nâng cao chất lượng, hiệu quả nghiên cứu và ứng dụng khoa học, công nghệ, đặc biệt là khoa học giáo dục và khoa học quản lý. Chủ động hội nhập và nâng cao hiệu quả hợp tác quốc tế trong giáo dục, đào tạo. 


\section{Kết luận}

"Văn hóa soi đường quốc dân đi” không chỉ dừng lại ở nghĩa định hình những giá trị bản sắc riêng có của cộng đồng của quốc gia dân tộc, mà trong xu thế cạnh tranh khốc liệt như hiện nay, văn hóa đã, đang và sẽ tiếp tục là động lực, lợi thế so sánh, tiềm năng, "vốn liếng" quan trọng nhất cho sự phát triển. Xây dựng phát triển con người là điều kiện tiên quyết để xây dựng thành công chủ nghĩa xã hội ở Việt Nam. Bởi "muốn xây dựng chủ nghĩa xã hội thì trước hết phải có những con người xã hội chủ nghĩa" như Chủ tịch Hồ Chí Minh từng căn dặn. Vì thế, việc xây dựng, hình thành nên những người Việt Nam có phẩm chất, năng lực, "vừa hồng vừa chuyên" là nhiệm vụ trọng tâm trong các chương trình, kế hoạch của các cấp, các ngành.

\section{TÀI LIẸU THAM KHẢO}

1. Đảng Cộng sản Việt Nam (1986), Văn kiện Đại hội đại biểu toàn quốc lần thư VI, Nxb Sự thật, Hà Nội.
2. Đảng Cộng sản Việt Nam (1996), Văn kiện Đại hội đại biểu toàn quốc lần thư VIII, Nxb Chính trị quốc gia, Hà Nội.

3. Đảng Cộng sản Việt Nam (1998), Văn kiện Hội nghị lần thứ năm Ban chấp hành Trung uoong khóa VIII, Nxb Chính trị quốc gia, Hà Nội.

4. Đảng Cộng sản Việt Nam (2011), Văn kiện Đại hội Đại biểu toàn quốc lần thứ XI, Nxb CTQG, Hà Nội.

5. Đảng Cộng sản Việt Nam (2014), Văn kiện Hội nghi lần thứ chín Ban chấp hành trung uoong khóa XI, Văn phòng Trung ương đảng, Hà Nội.

6. Đảng Cộng sản Việt Nam (2016), Văn kiện Đại hộ đại biểu toàn quốc lần thứ XII, Văn phòng Trung ương Đảng, Hà Nội.

7. Nguyễn Đình Minh (2004), Đề cuoong về văn hóa Việt Nam năm 1943 - Giá trị lịch sử và hiện thực. Nxb QĐND, Hà Nội.

\section{The thinking development of the Communist Party about construction of culture and Vietnamese people in the new era}

\section{Bui Bach Dang}

\section{Article info}

\section{Recieved:}

30/12/2019

Accepted:

$10 / 3 / 2020$

Keywords:

Theoretical thinking of the Communist Party of Vietnam;

Vietnamese culture; era of renewal

\begin{abstract}
Culture plays a very important role in social life, culture is always going ahead to open the way, accompanying to gather signs and following to complete social revolutions. In the process of leading the revolution, the Communist Party of Vietnam has made new developments in the theoretical thinking about culture and the people of Vietnam, so that culture truly becomes the spiritual foundation of society, both as goals, and motivating the country's sustainable development.
\end{abstract}

